\title{
MRES
}

Res Mobilis

Revista internacional de investigación en mobiliario

y objetos decorativos

Vol. $5, \mathrm{n}^{\circ} .6$ (I), 2016

\section{LA COMODA ISABELINA CATALANA COMO AGLUTINANTE DE LAS ARTES APLICADAS Y LAS INFLUENCIAS EUROPEAS \\ THE CATALAN ISABELINA COMODA AS AGGLUTINANT OF APPLIED ARTS AND \\ EUROPEAN INFLUENCES}

Joan Güell Solà ${ }^{*}$

Associació per a l'estudi del moble

\section{Resumen}

Este estudio pretende concretar al máximo la evolución decorativa, estructural de la cómoda y determinar cuáles son las referencias europeas que influyen durante el periodo isabelino. Empezamos analizando los modelos del periodo Fernandino por la enorme trascendencia que tienen durante buena parte del siglo XIX hasta el inicio del periodo Alfonsino. Esta tipología durante el siglo XIX tiene la capacidad de ser un buen marco de expresión para que muchos artesanos, diseñadores y ebanistas demuestren su pericia decorativa y originalidad. Así la aplicación de numerosas técnicas decorativas junto con la aparición de las influencias europeas marcarán la belleza de estas piezas. El estudio analiza una cantidad importante de muebles buscando originalidad estructural, decorativa y compositiva para determinar que esta evolución sea lo más exacta posible.

Palabras clave: cómoda, mueble, siglo XIX, Isabelino, Cataluña.

\section{Abstract}

This study aims to realize the most decorative, structural evolution of the commode and determine which references European influence during the Elizabethan period are. We started analyzing models Fernandino period by the enormous importance they have for much of the nineteenth century until the beginning of Alfonsino period. This typology during the nineteenth century has the ability to be a good frame of expression for many artisans, designers and cabinetmakers to demonstrate their expertise and decorative originality. Thus the application of numerous decorative techniques along with the emergence of European influence will make the beauty of these pieces. The study analyzes a lot of number of furniture looking for structural, decorative and compositional originality to determine that this evolution is as accurate as possible.

Keywords: commode, furniture, nineteenth century, Elizabethan, Catalonia.

*E-mail: joanguell@hotmail.es 
La cómoda en Cataluña, durante el siglo XIX, será una tipología donde se plasman muchas de las influencias y corrientes decorativas que aparecen en Europa y al mismo tiempo, tendrá un carácter muy propio de la zona sin olvidarse de buscar una buena calidad. El estudio realiza una evolución cronológica de los diferentes periodos artísticos, pero hay que tener en consideración que las fechas expuestas son orientativas. Las corrientes, las referencias, las influencias europeas llegarán a España y a Cataluña de manera constante y es difícil determinar de manera exacta cuando se expanden. Así a través de las decoraciones, las formas, los materiales se intentará llegar a conclusiones lo más exactas posibles.

El estudio lo iniciamos con la cómoda del periodo fernandino que tiene una clarísima relación con el mobiliario de la época Imperio francesa. Cronológicamente abarcaría de 1813 hasta 1830 aproximadamente. En Cataluña y otros muchos lugares de la península el acercamiento al mobiliario francés se aprecia de manera clara. Hay zonas de España donde es muy evidente, como por ejemplo en Madrid, donde la aproximación es tal que se llegan a importar piezas directamente de Francia y se realizarán copias de similares características.

La cómoda sigue las mismas características del mobiliario imperio pero con una gran diferencia: la construcción interior es mucho más simple y menos robusta ya que se utilizarán maderas blandas de la zona y más económicas como el chopo y toda clase de maderas blandas. En Europa, excepto en la zona mediterránea, se utilizará mayoritariamente el roble para esta estructura interior dando así mayor robustez y pesadez al mueble. Para el exterior se utilizarán maderas nobles como la caoba o palma de caoba, normalmente en chapas, y para las piezas más sencillas y populares, el nogal macizo. La ornamentación sigue los mismos modelos franceses Se utilizará la talla dorada casi exclusivamente como única técnica decorativa aplicada, dejando de lado el bronce dorado tan usado en Francia en este periodo. Los motivos decorativos más utilizados son: esfinges, palmetas, águilas, delfines, garras de león y diferentes elementos clásicos. (Fig.1.). En esta cómoda encontramos la decoración tallada en los capiteles y bases de las columnas y los tiradores con águilas imperiales marcando estilo.

Como podemos apreciar, el primer cuarto del siglo XIX, aparece una cómoda muy distinta a la del siglo XVIII. Una de las principales razones de esta transformación es el seguimiento que hacen los ebanistas y artesanos de las modas europeas: sobre todo de Francia, Alemania, Inglaterra y algunas referencias puntuales italianas como veremos. Si analizamos estructuralmente la cómoda de este periodo apreciamos un cuerpo central con tres cajones enmarcados por dos columnas y coronados por un cajón superior y uno de inferior -este último no aparece en todos los modelos- que sobresalen y adoptan generalmente perfiles sinuosos y elegantes rompiendo así la pesadez del mueble Imperio francés. (Fig.1.). Encontramos también algunos ejemplos con un 
movimiento exagerado de su estructura en la parte inferior, esta característica aparece, generalmente, cuando nos acercamos al primer cuarto del siglo XIX aproximadamente. (Fig. 2.). Se introduce lentamente el mármol de color blanco en el sobre de la cómoda. A parte de la talla, mencionada anteriormente, la marquetería es la otra técnica decorativa que aparece de manera habitual. En un primer momento la talla tiene una mayor presencia y la marquetería aparecerá de manera puntual. A partir de estos ejemplos la cómoda va evolucionando lentamente durante todo los años posteriores como veremos.

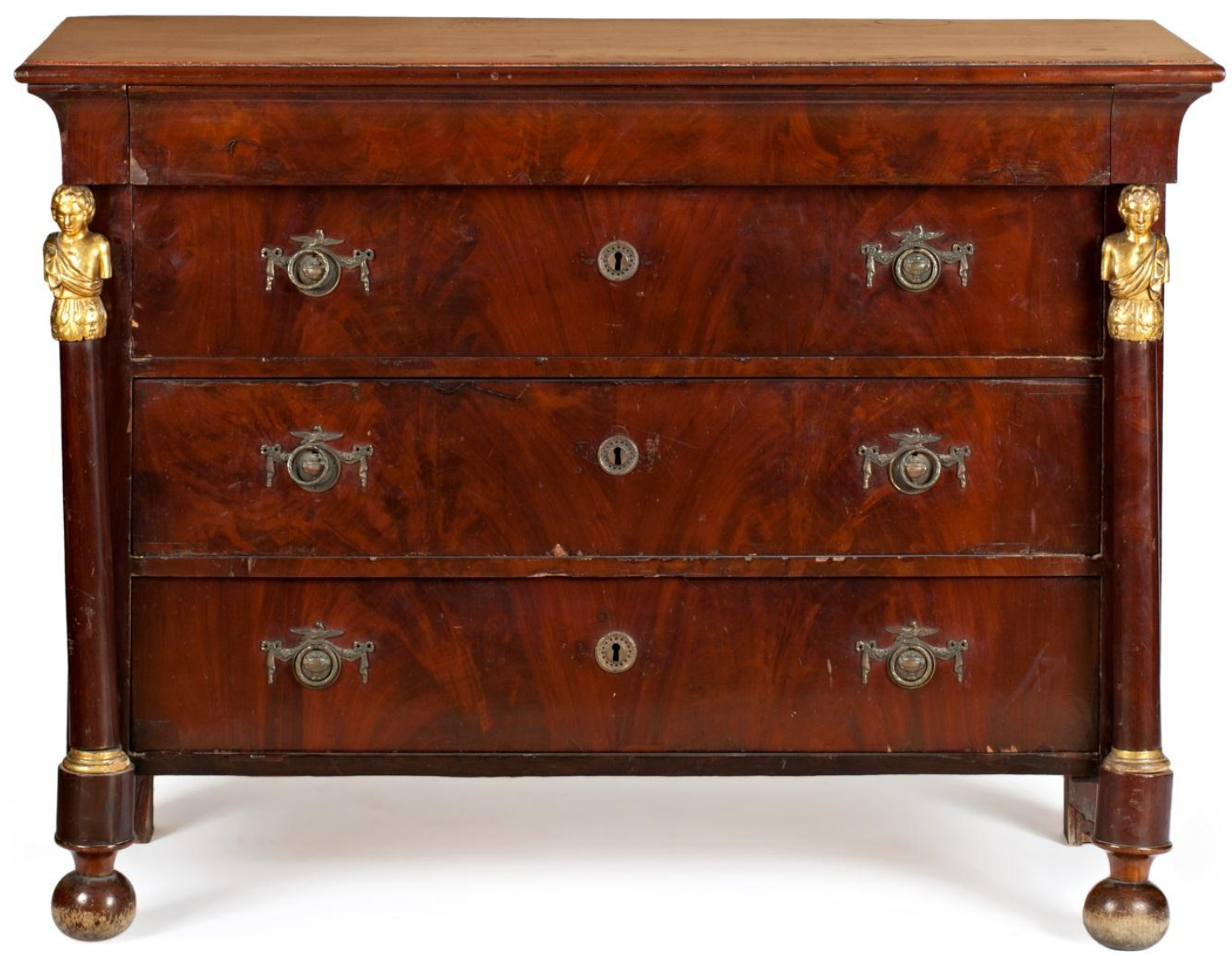

Fig. 1. Cómoda Fernandina de palma de caoba, de hacia 1815. 


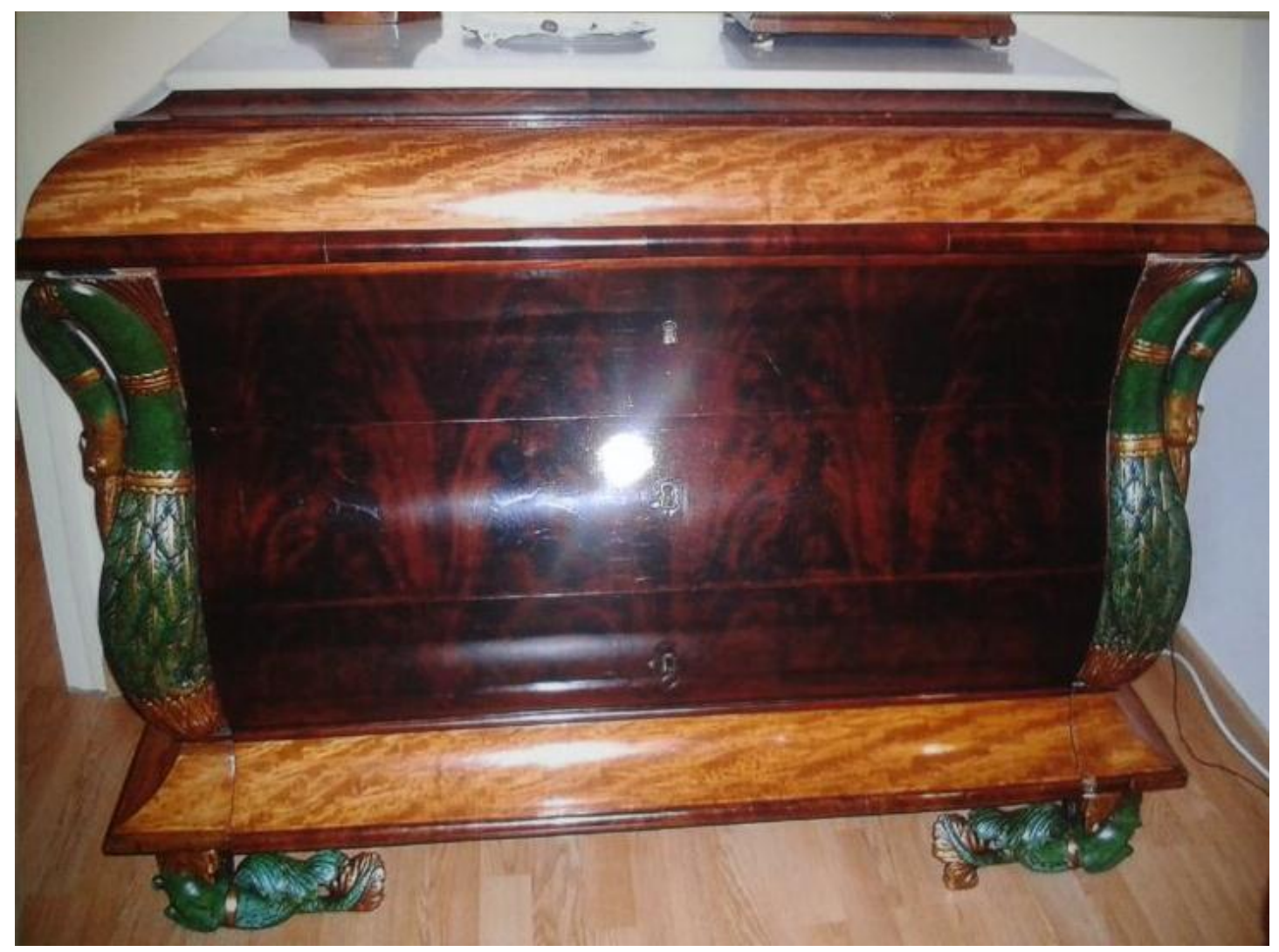

Fig. 2. Cómoda Fernandina de palma de caoba y tallas doradas y patinadas, de hacia 1825.

Durante la década de 1820-30 la cómoda sigue nuevamente los modelos Imperio pero incorporará pequeños detalles que nos ayudarán a ver la evolución que se está produciendo. Se introducirán las maderas claras que serán utilizadas para resaltar ciertas partes del mueble -cajón superior, inferior y chaflanes laterales-. (Fig.2.). Esta característica la relacionaremos directamente con los modelos del periodo Restauración francés (1815-1830) y el estilo Biedermeier alemán ( 1815-48) que utilizarán maderas claras, casi exclusivamente, para chapar el mobiliario. Esta característica nos ayudará fechar con más facilidad el mobiliario que las usan puesto que la utilización de maderas con tonos suaves no será muy habitual durante el siglo XIX. En algunas piezas sorprende la originalidad e incluso podríamos citar la "rareza" que poseen algunas estructuras, como por ejemplo: la aparición de doseles en la parte inferior -más típico en Mallorca que en Cataluña- (fig. 3), combinaciones novedosas utilizando líneas rectas y curvas en una misma pieza. (Fig. 4). Es importante mencionar que los talleres industriales aún no han alcanzado su gran esplendor, por este motivo, el mobiliario todavía se elabora de forma básicamente artesanal y no mecanizada como sucederá a partir de mediados de siglo. La consecuencia más directa de este hecho es que este mobiliario será de buena calidad y original en numerosos casos.

Durante el periodo de 1830 a 1845 aproximadamente, denominado Regencia María Cristina, las artes decorativas evolucionarán hacia un 
eclecticismo: se produce la búsqueda de un estilo propio mirando el pasado y al mismo tiempo las influencias extranjeras del momento. Europa volverá a ser una gran fuente de inspiración para los ebanistas y artesanos de la época que seguirán copiando y asimilando las mismas referencias, recursos técnicos y materiales. La influencia principal aún será del estilo imperio y se le sumarán nuevamente las características del periodo Restauración francés.

Una vez estudiadas una cantidad importante de ejemplos podemos llegar a las siguientes conclusiones: persiste la herencia de las décadas pasadas pero observaremos como la cómoda se va transformando y adaptando a los nuevas corrientes. Por ejemplo, el primer cajón lo encontramos con perfiles curvos o triangulares, aparecen diferentes fajas decorativas rectangulares, generalmente de pequeñas dimensiones, en la parte superior y inferior, persisten los laterales achaflanados ondulados o rectos decorados con marqueterías, los tres cajones centrales siguen realizando una composición unitaria y compacta -sin tiradores en numerosos casos- y con pequeños protectores de llaves de latón, el cajón inferior generalmente con movimiento y las patas son torneadas o en forma de disco o medio disco. Persisten las mismas maderas utilizadas hasta el momento: palma de caoba, nogal y la estructura de madera de río. Las maderas claras se siguen presentes y se colocarán generalmente en el primer cajón, en el último, en chaflanes y en pequeñas franjas horizontales entre el mármol y el primer cajón generalmente, pero también las podemos encontrar en otras zonas menos habituales como en franjas inferiores.

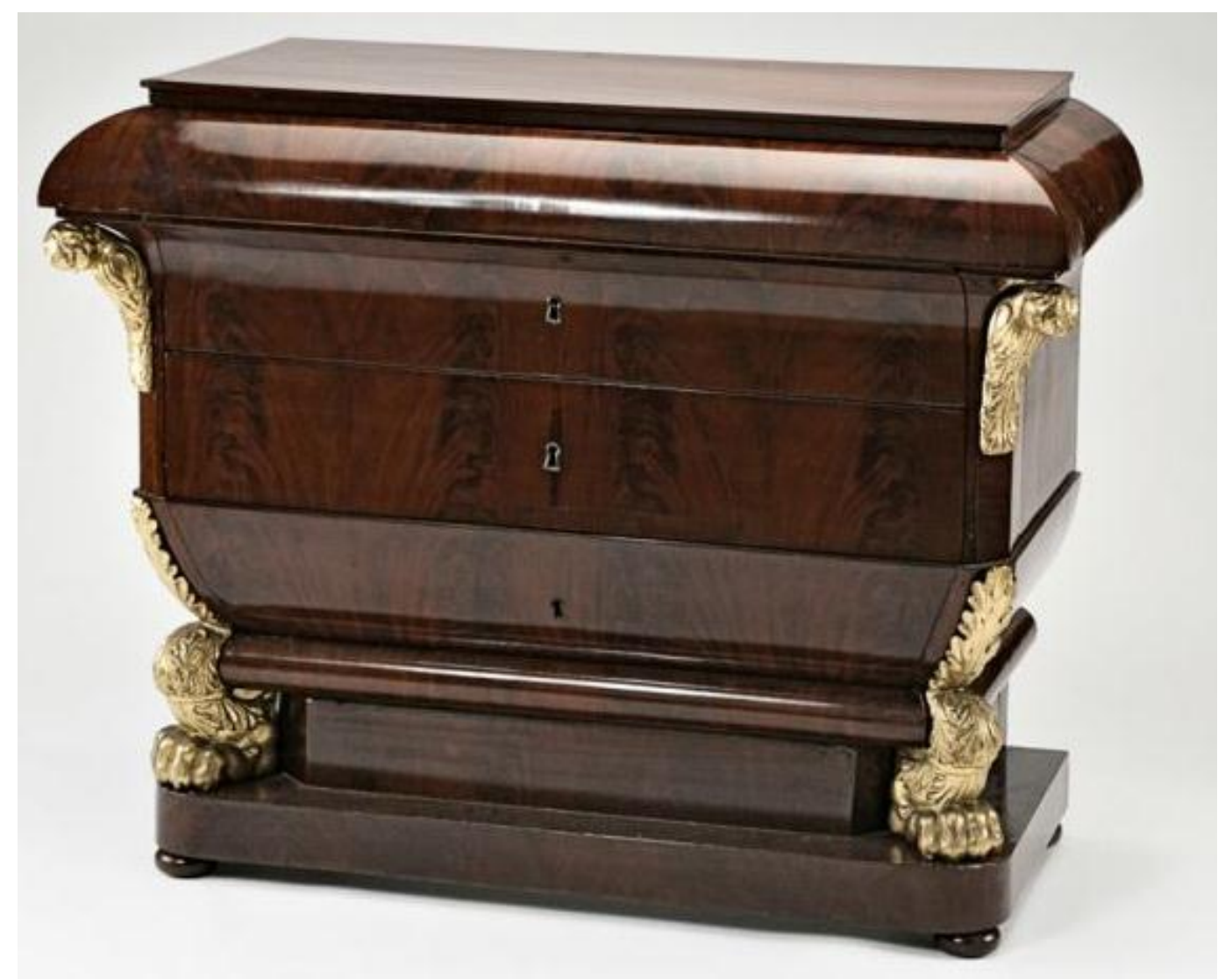

Fig. 3. Cómoda Fernandina de palma de caoba y tallas doradas, de hacia 1825. 


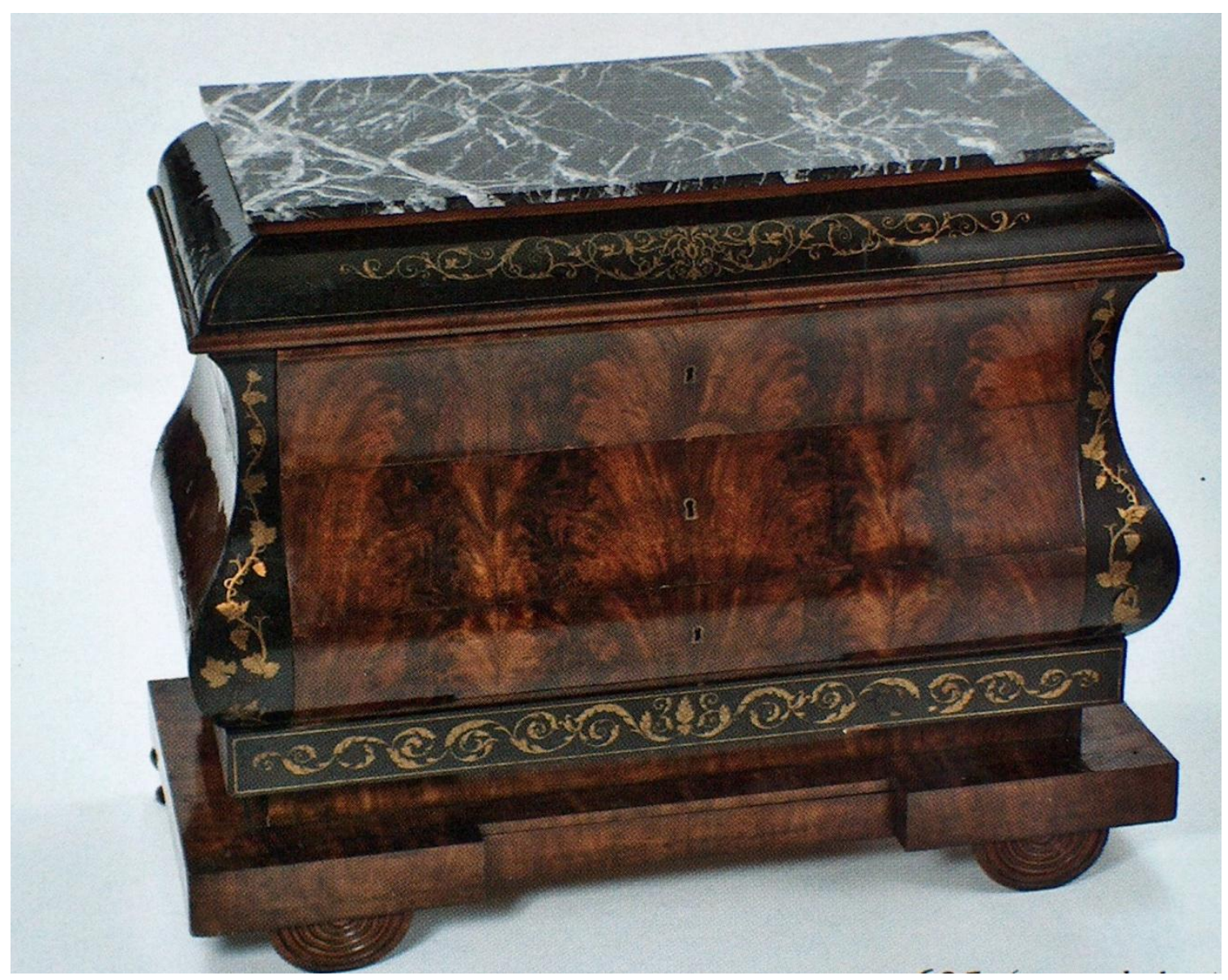

Fig. 4. Cómoda regencia María Cristina de palma de caoba y madera de palisandro, de hacia 1835.

La temática de las marqueterías es la misma de las décadas pasadas referencias al estilo imperio- pero lentamente van desapareciendo y reduciendo sus proporciones, volviéndose así más equilibradas y finas. Poco a poco se introducirán temas románticos, como referencias al estilo gótico: arcos ojivales ocupando toda la superficie de los tres cajones centrales o las puertas de los ejemplares que son "à vantaux"- aparecen en este momento en Cataluña - (fig. 5) y rosetones imitando las vidrieras de las catedrales. En las exposiciones industriales de la época encontraremos referencias al gusto gótico: el ebanista José Balmalla presenta "una mesa de caoba al estilo gótico"1. También nos encontramos decoración de clara influencia oriental: personajes orientales con sus características vestimentas agarrando sombrillas y aparecen también pagodas o paraguas que coronan diferentes decoraciones. En algunas ocasiones estas dos referencias las encontraremos en un mismo mueble. En el museo de Arte de Girona aparece una cómoda, de este periodo, con influencias orientales pero realizadas con la técnica del micro mosaico, muy típico en la zona de Sorrento, Nápoles, conocida también con el nombre de marquetería de Sorrento. (fig. 6 y 7.). Las cómodas más populares aparecerán temas relacionados con la vida del campo o escenas cotidianas o amorosas: pescador en un río, cazadores, damas jugando con perros, etc. Esta temática seguirá en años posteriores. 


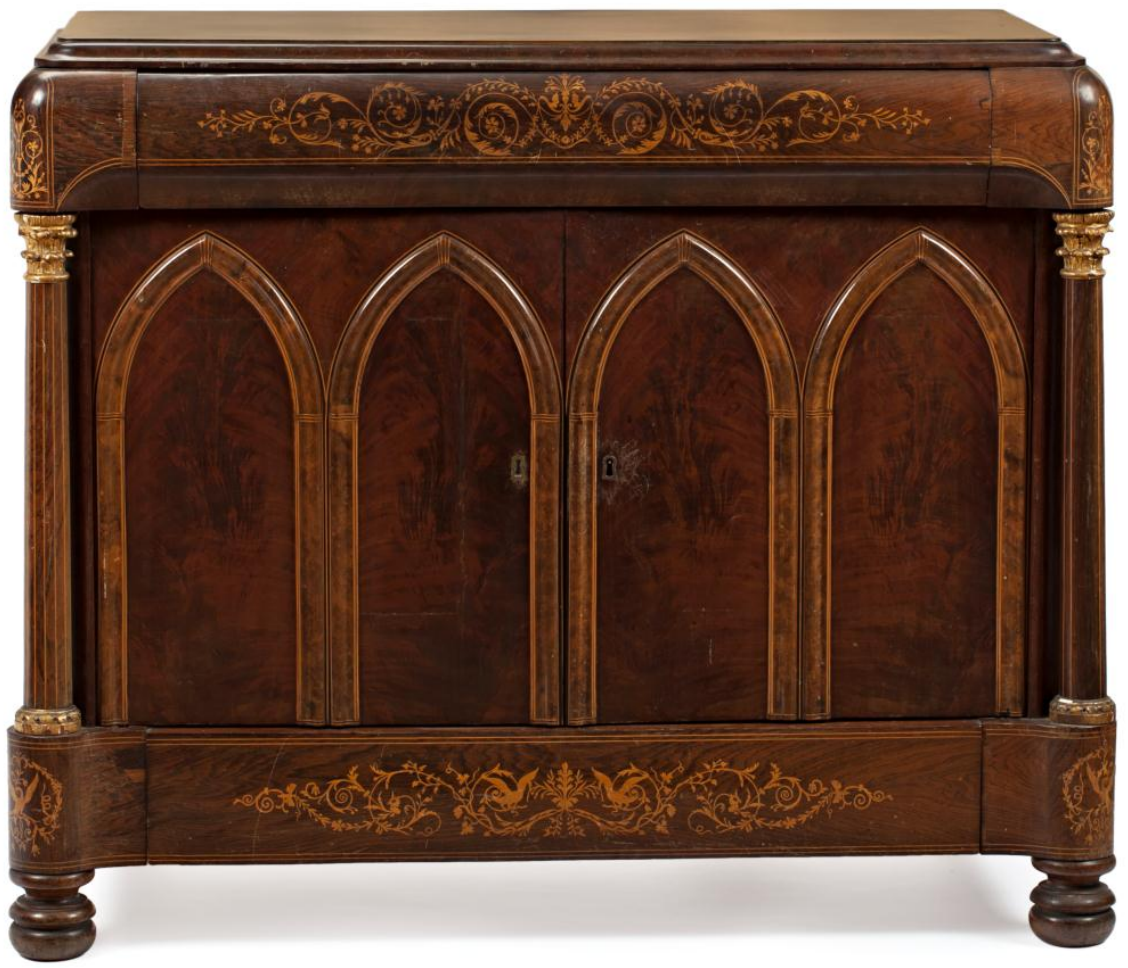

Fig. 5. Cómoda de estilo Gótico de palma de caoba y palisandro, de hacia 1840.

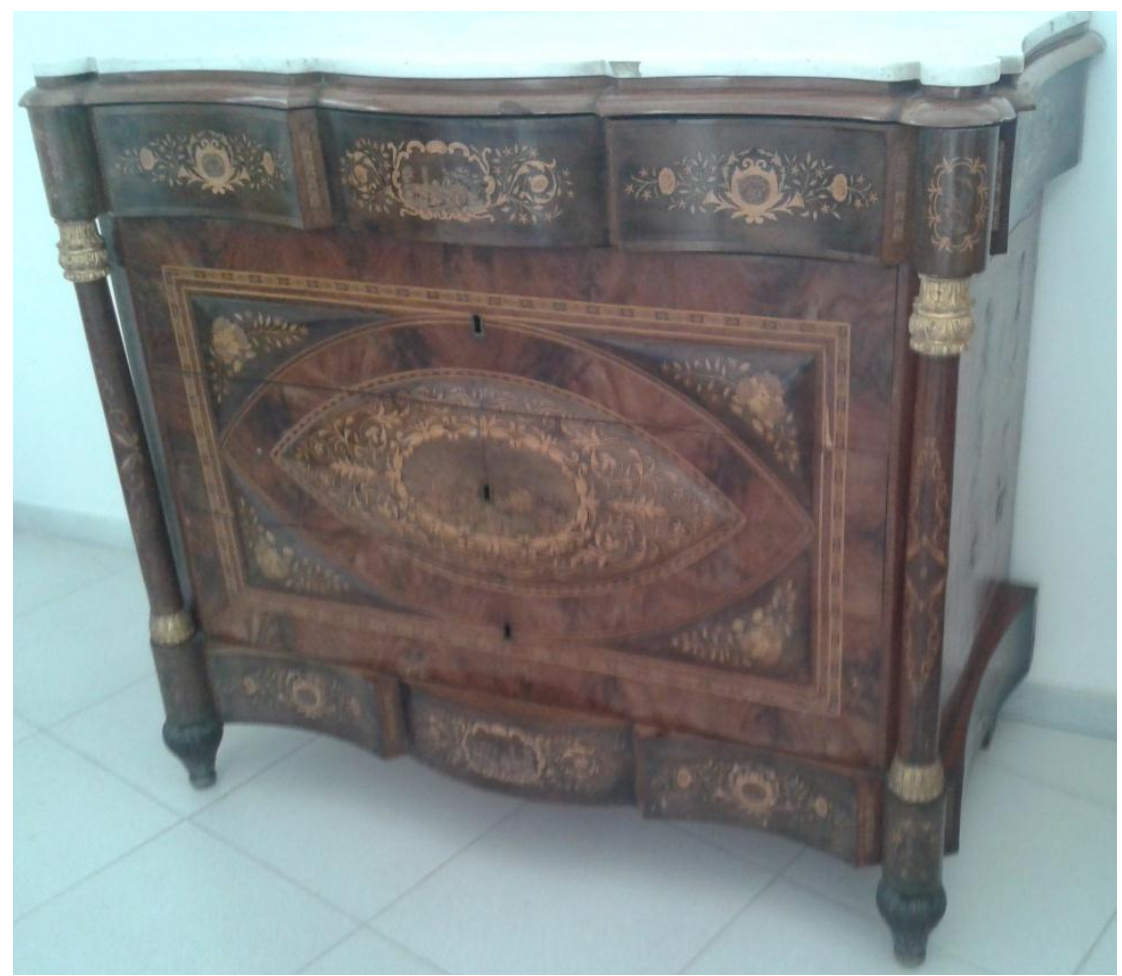

Fig. 6. Cómoda Isabelina con marquetería de Sorrento del Museo de Arte de Girona, de hacia 1845-50. 


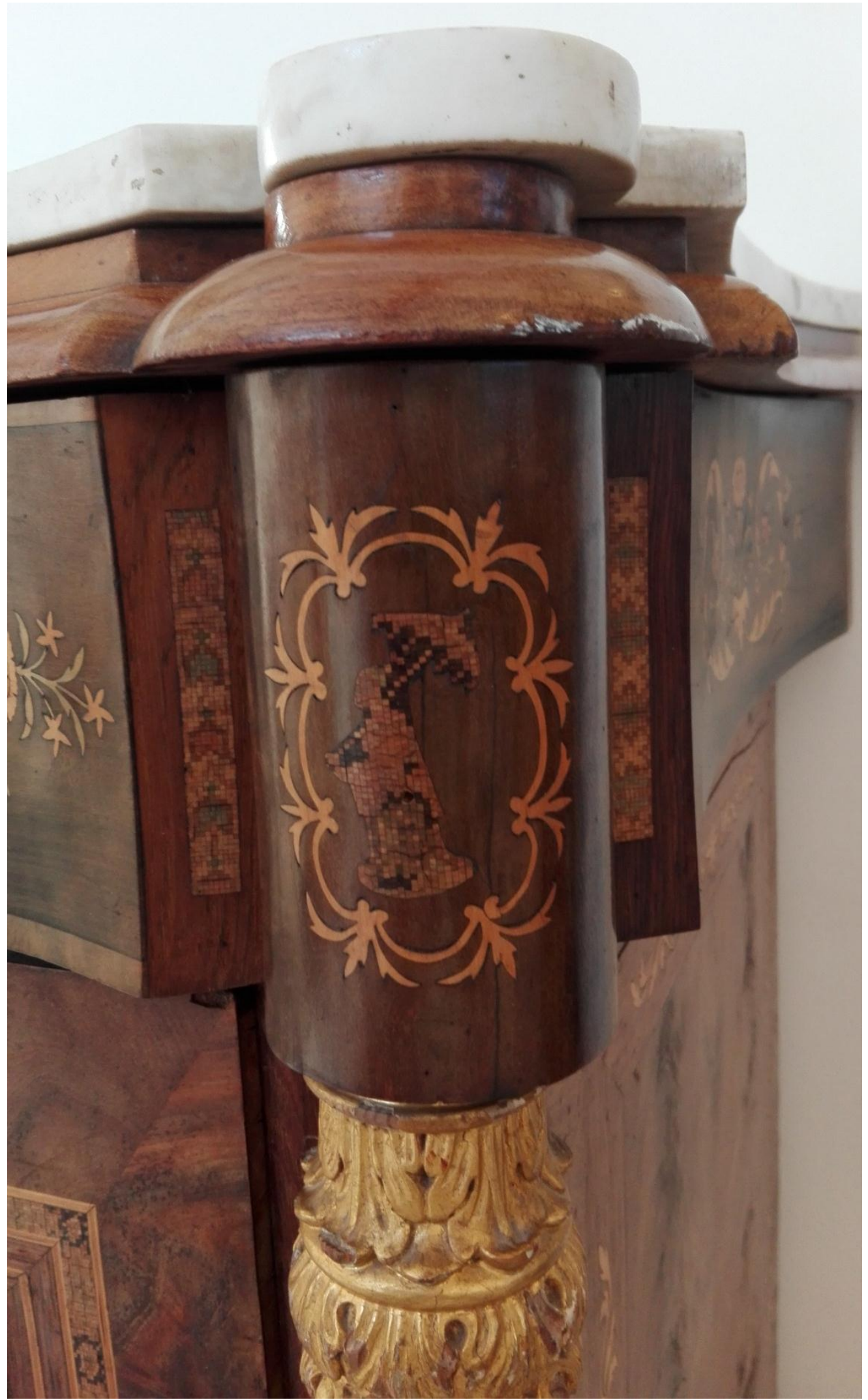

Fig. 7. Detalle de influencia oriental realizado con marquetería de micro mosaico. Cómoda del Museo de Arte de Girona. 
Un elemento a tener en consideración y que posteriormente tendrá una gran peso específico es la lenta introducción de las maderas oscuras a partir de 1835-40: por ejemplo el palisandro, el ébano y la madera tintada. En este periodo las encontraremos en lugares muy puntuales. Se utilizan sobre todo para resaltar y dar protagonismo a las marqueterías buscando un juego de tonos y contrastes cromáticos. Este hecho no es un elemento extraño, en Francia a partir del reinado de Loius Philipe (1830-48) las maderas de tonos oscuros se ponen de moda. Si analizamos las cómodas francesas observaremos que se asemejan muchísimo a las catalanas, tanto a nivel estructural como ornamental. La forma y la temática utilizada en las marqueterías también es muy similar - roleos vegetales entrelazados-. Las maderas son las mismas: palisandro y ébano sin olvidar las lacadas en negro pero también utilizan el nogal o raíz de nogal. La consecuencia directa de este cambio es que la palma de caoba y la caoba perderán importancia y se utilizarán cada vez menos para embellecer el mueble.

A partir de 1840 aproximadamente, en Europa se recuperarán los estilos más importantes del siglo XVIII: Luís XIV, XV y XVI. Así nos encontramos que las características del Barroco, del Rococó y del Neoclásico aparecerán de manera combinada, dando originalidad al mobiliario y haciéndolo indudablemente ecléctico. Se busca en este periodo realizar un mueble decorativo, exagerado, lleno de contrastes, utilizando todos los recursos que estén en las manos de los artesanos y decoradores. Así encontramos marqueterías a la manera "Boulle", utilizando maderas oscuras combinándolas con latón, zinc, carey, marfil y nácar. La temática de estas composiciones decorativas se asemejan a los grabados de Jean Bérain ${ }^{2}$ pero no se deja de lado los temas populares y tradicionales. Las estructuras de los muebles adaptarán mayoritariamente las formas Rococó, basándose en los de la época Louis XV, y este hecho no sucede exclusivamente en Francia sino en toda Europa. Así los mueble se realizarán utilizando formas sinuosas, serpentinas que contrastarán notablemente con la seriedad de los tonos oscuros y las marquetería a la manera "Boulle".

Estas referencias europeas entrarán aún con más fuerza a partir de 1850 y seguirán durante la década siguiente. Así, la cómoda catalana estructuralmente no recibe cambios importantes, constructivamente se asemeja a la de las décadas pasadas. Quizás la novedad más importante es el abombamiento que se produce desde la parte superior a la inferior, contrastando notablemente con el movimiento exagerado de abajo a arriba que se producía desde la época fernandina. (Fig. 8.). La causa más probable de este cambio puede ser fruto de la introducción del gusto Rococó y la recuperación nuevamente de las cómodas de estilo Luis XV que se realizarán en Francia. En estas el movimiento empieza lentamente en la parte superior y se acentúa en los cajones centrales y posteriormente disminuye lentamente en la parte inferior. Hay que mencionar que el primer cajón adopta movimientos más exagerados tanto de manera lateral como horizontal.

Las marqueterías siguen siendo el gran recurso decorativo para embellecer la cómoda y el mobiliario en general. El juego de chapas y de materiales preciosos darán lugar a unas piezas de gran originalidad y perfección 
técnica. La madera de palisandro ya ocupará toda la superficie del mueble en numerosos ocasiones, buscando contrastes con los tonos brillantes y claros del latón, el zinc, el nácar, el marfil y el carey. (Fig. 7). La documentación de la época nos demuestra la utilización de manera habitual de materiales preciosos combinados con palisandro y ébano, por ejemplo en los catálogos se cita: “ D.JUAN NOLIS (...) cuatro sillones de ébano, con embutidos de concha y metal cincelado (...) D. ESTÉBAN CANALS, de Barcelona,(...) una cama de pabellón, dos cómodas y un armario con espejo, todo de palisandro, D. JUAN ANTONIO CABANERAS, de Barcelona (...) una mesa redonda para salón, tablero de dos Varas de diámetro y de una sola pieza con incrustaciones de metal" ${ }^{3}$. Los elementos representados en estas marqueterías recuerdan notablemente la temática naturalista que se realizará durante la primera mitad del siglo XIX. Se sigue introduciendo todo repertorio decorativo cercano a Jean Bérein y ya definitivamente no encontraremos la influencia del primer cuarto del siglo XIX. Complementando las marqueterías aparecen fileteados enmarcando todos los perfiles de los cajones y muchas de las composiciones que aparecerán. Un elemento novedoso de la época es la "cadeneta": composición lineal y repetitiva de pequeñas piezas de metal y de madera de formas geométricas que enmarcan diferentes decoraciones o los perfiles del mueble, estas pueden ser más elaboradas o menos dependiendo de la calidad del mueble. (Fig. 9.)

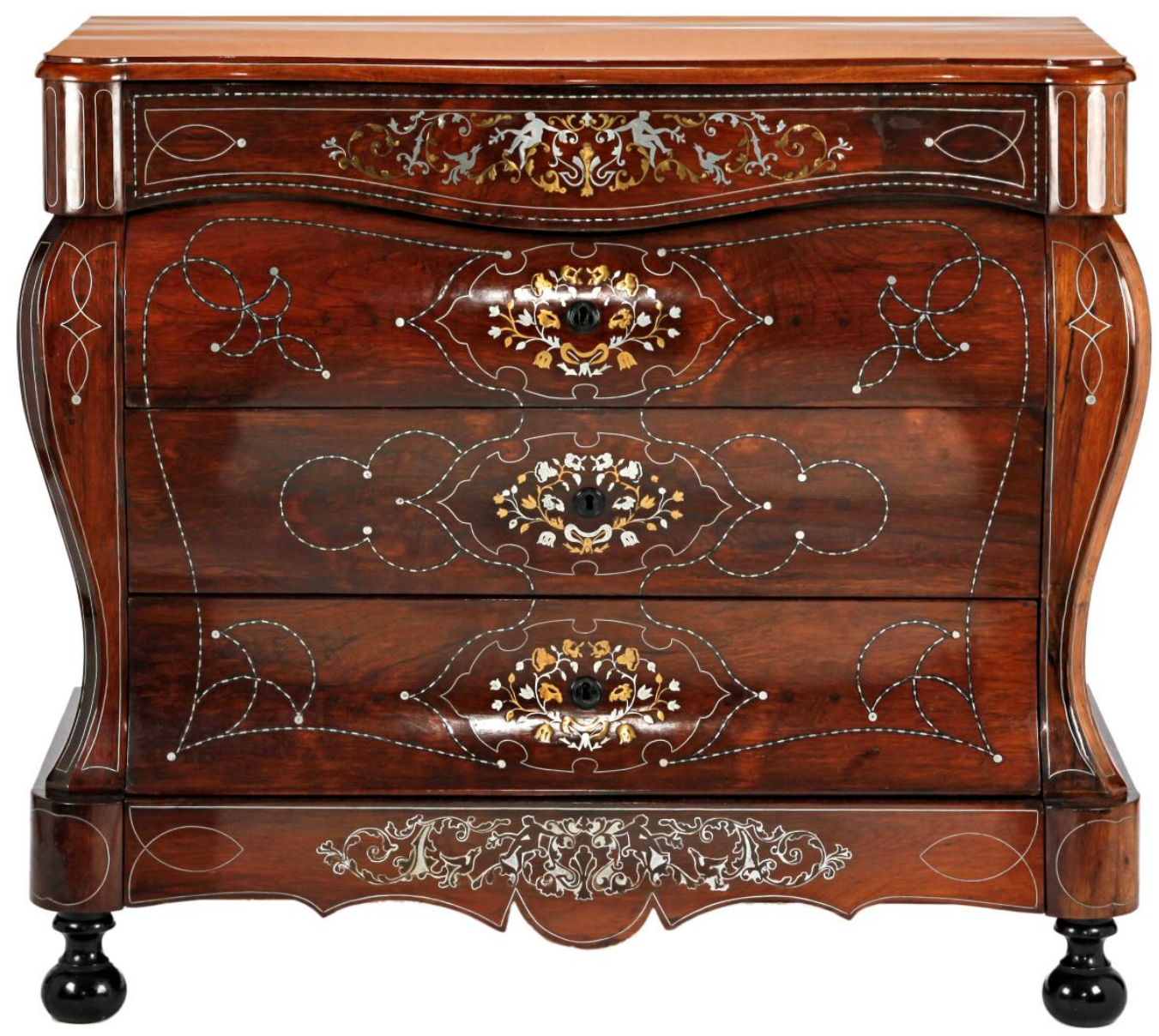

Fig. 8. Cómoda Isabelina de palisandro y marquetería metálica, de hacia 1850. 

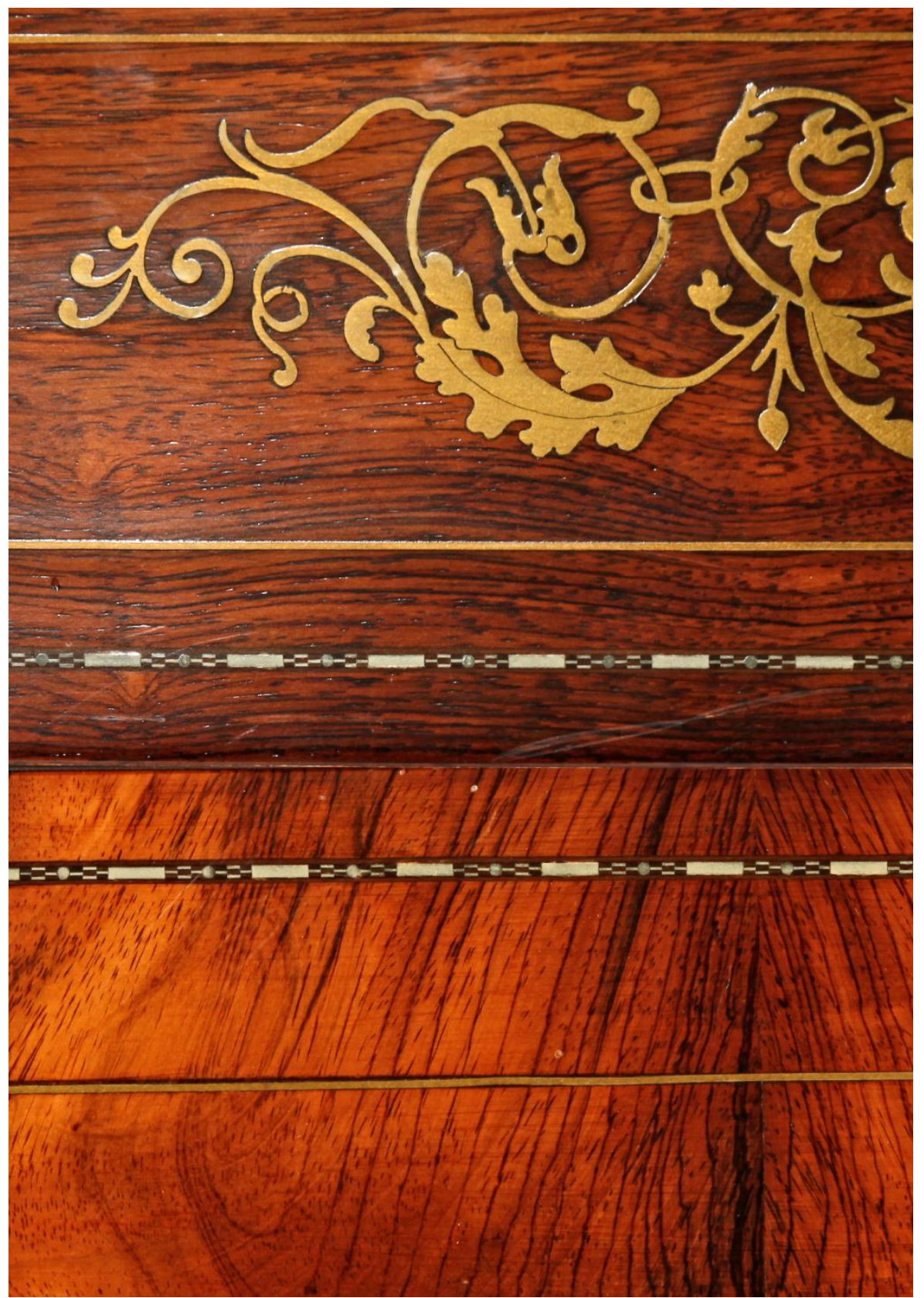

Fig. 9. Detalle de marquetería metálica y cadeneta de una cómoda Isabelina, de hacia 1850.

Durante este periodo también encontraremos otro modelo de cómoda que no jugará con el movimiento de la estructura pero tendrá características similares a nivel de los materiales utilizados y técnicas decorativas aplicadas. Esta es la misma que hemos visto evolucionar lentamente durante la primera mitad del siglo XIX: mueble recto de cinco cajones - uno superior, tres centrales con decoración unitaria y uno inferior- con columnas laterales enmarcando la pieza. El cajón superior y el inferior que enmarca la decoración central introducirá un movimiento cóncavo convexo horizontal muy elegante y al mismo tiempo en centro aumenta su tamaño. En los cajones centrales aparecen formas ovaladas, redondas, cuadradas incluso elementos parecidos a escudos heráldicos. 
En algunos ejemplos sobresalen de la base de los cajones dando así un relieve novedoso a la pieza. Estos modelos recuerdan las composiciones decorativas que se producen durante el periodo Napoleón III en Francia (1848-1871). Estas cómodas sorprenden porqué utilizarán un número importante de tipos de maderas y no exclusivamente el palisandro como sucede con las que utilizan la marquetería de metal. Así en algunos ejemplos utiliza hasta seis tipos de manera distintos: palisandro, palma de caoba, raíz, nogal, ébano y boj. (Fig. 10.). En algunos ejemplos, como la que se encuentra en el Museo Víctor Balaguer de Vilanova y la Geltrú se llega incluso a la exageración decorativa y al "horror vacui"4. La decoración marqueteada ocupa toda la superficie del mueble, los laterales, la parte central con los medallones y los cajones, son muy pocos los ejemplares con esta exageración decorativa. (Fig. 11.)

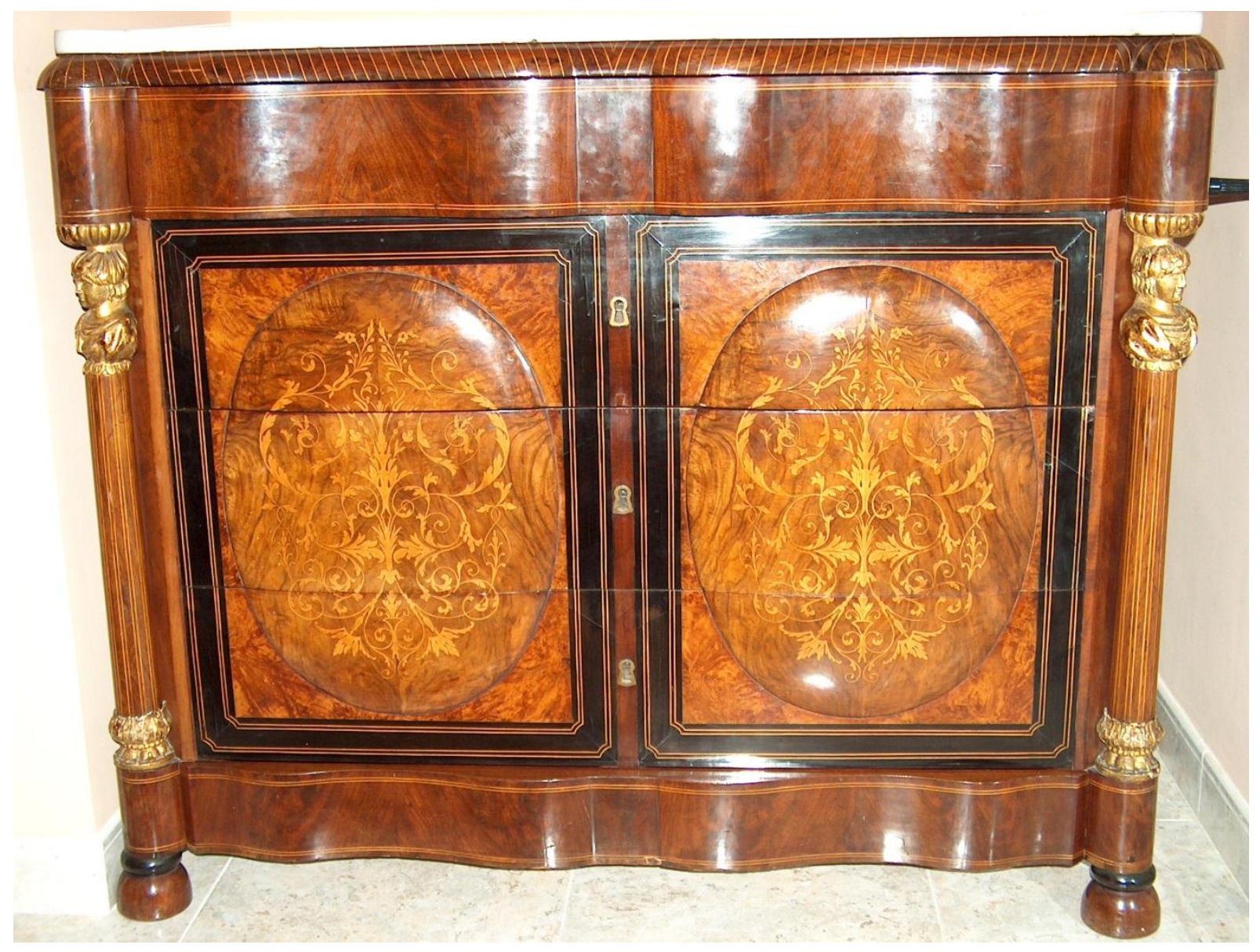

Fig. 10. Cómoda Isabelina de influencia Napoleón III, de hacia 1850-55. 


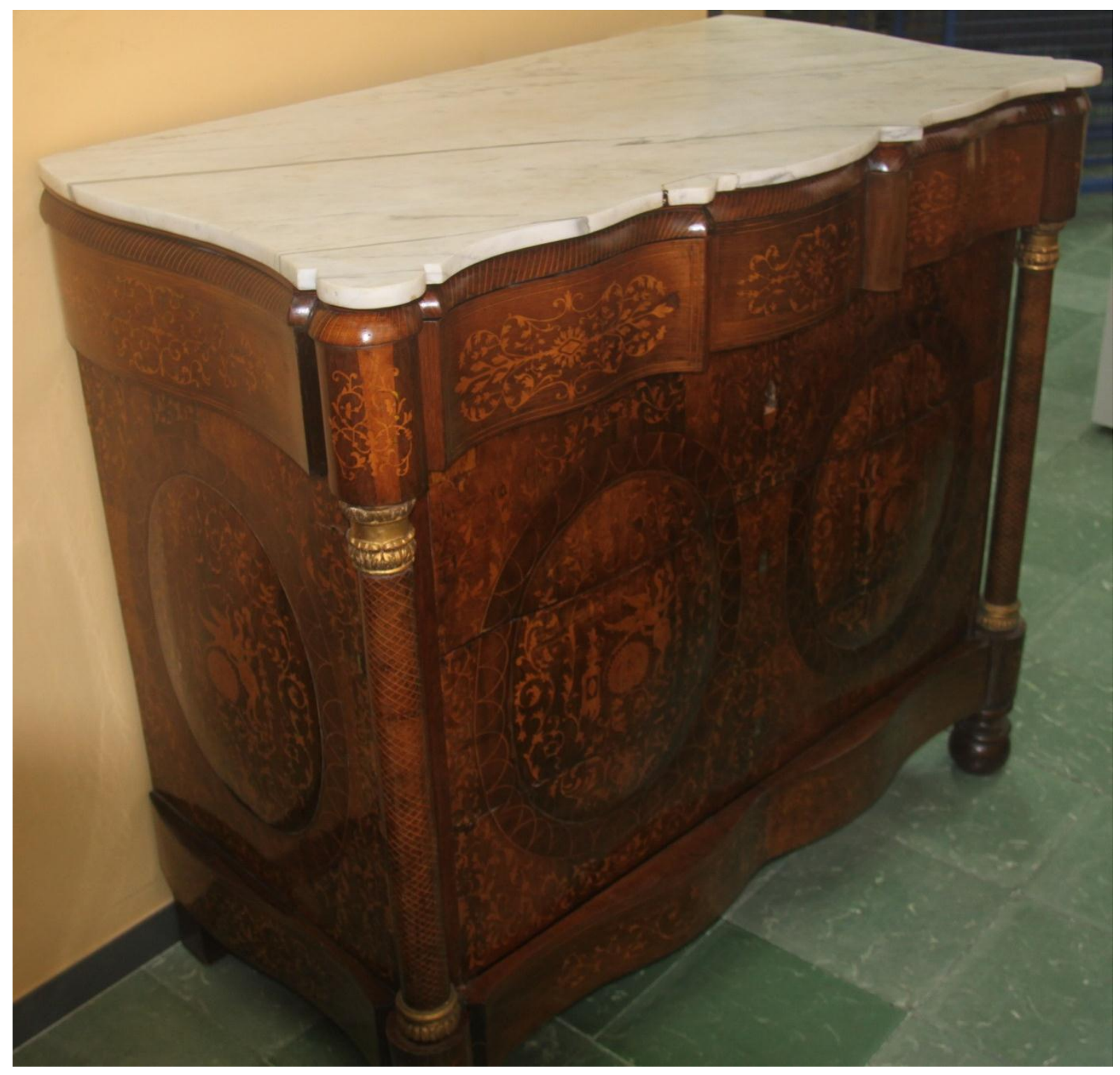

Fig.11. Cómoda de palisandro del Museo Víctor Balaguer de Vilanova y la Geltrú.

Una de las técnicas que recuperará su presencia y en las últimas décadas había perdido protagonismo es la talla. Cuando el gusto por el estilo Imperio va decreciendo se observa que los artesanos la van dejando de utilizar. A partir de 1830 hemos observado que los soportes generalmente son torneados, los chaflanes están ocupados por columnas y en las cómodas con movimiento los laterales son lisos y juegan con la pureza de líneas, en conclusión, en los posibles lugares donde la talla podía tener presencia se ha optado por otras soluciones como hemos visto. En Europa sucede algo semejante. En este periodo Alemania, Francia y en menor medida Inglaterra disminuye la aplicación de la talla en el mobiliario y se prefieren las superficies lisas o con marqueterías decorativas. Podríamos citar que a partir 1850 la talla va adquiriendo protagonismo lentamente y en la siguiente década es cuando tiene una mayor presencia. La 
cómoda en este tercer cuarto del siglo XIX sigue básicamente los modelos vistos anteriormente incorporando tallas en los laterales.

Las piezas de este periodo son un resumen de todo lo que sucede durante la primera mitad del siglo XIX. Encontramos ejemplos de una gran maestría técnica con exageradísimos movimientos, aplicación de materiales preciosos poco utilizados en Cataluña para embellecer las cómodas, como es el carey. Las dos localizadas que utilizan este material encontramos este material enmarcando los bocallaves y se combina con marquetería de latón. (Fig.12.). También nos encontramos piezas más sencillas y menos espectaculares. (Fig. 13.). Los muebles se seguirán realizando con maderas de tonos oscuros y poco a poco la presencia del color negro tendrá más importancia como se observa en el periodo Alfonsino. Este hecho lo demuestra las facturas de algunos talleres artesanales como el de Juan Pibernat donde emite una factura en fecha de 23 de mayo de 1867 citando: "1 cama de71/4 palmos $\mathrm{n}^{\circ} 4$ a la inglesa maqueada encernada con pabellón". Este documento nos demuestra la presencia del "maque" 5 en la década de 1860 y poco a poco adquirirá una gran importancia posteriormente.

En conclusión, este estudio intenta demostrar la importancia que tienen las corrientes europeas en la construcción, decoración y embellecimiento del mueble catalán del siglo XIX. Para finalizar exponer dos ejemplos, uno catalán y otro francés fechados aproximadamente hacia 1865-70 de gran similitud. Estructuralmente siguen una composición muy similar: dos puertas centrales, laterales chaflanados y cajón superior. Decorativamente utilizan la marquetería de metal, pero en una utiliza el nácar, y el palisandro y la otra el carey con el ébano o madera lacada. Se aplican elementos ornamentales en los chaflanes de temática clásica como son las ménsulas pero se utilizan diferentes materiales para su construcción. La catalana utiliza la talla dorada y la francesa el bronce dorado. (Fig. 14 y 15.) En resumen, estos dos ejemplos nos demuestran un gran parecido formal y al mismo tiempo un distanciamiento importante en los materiales utilizados. 


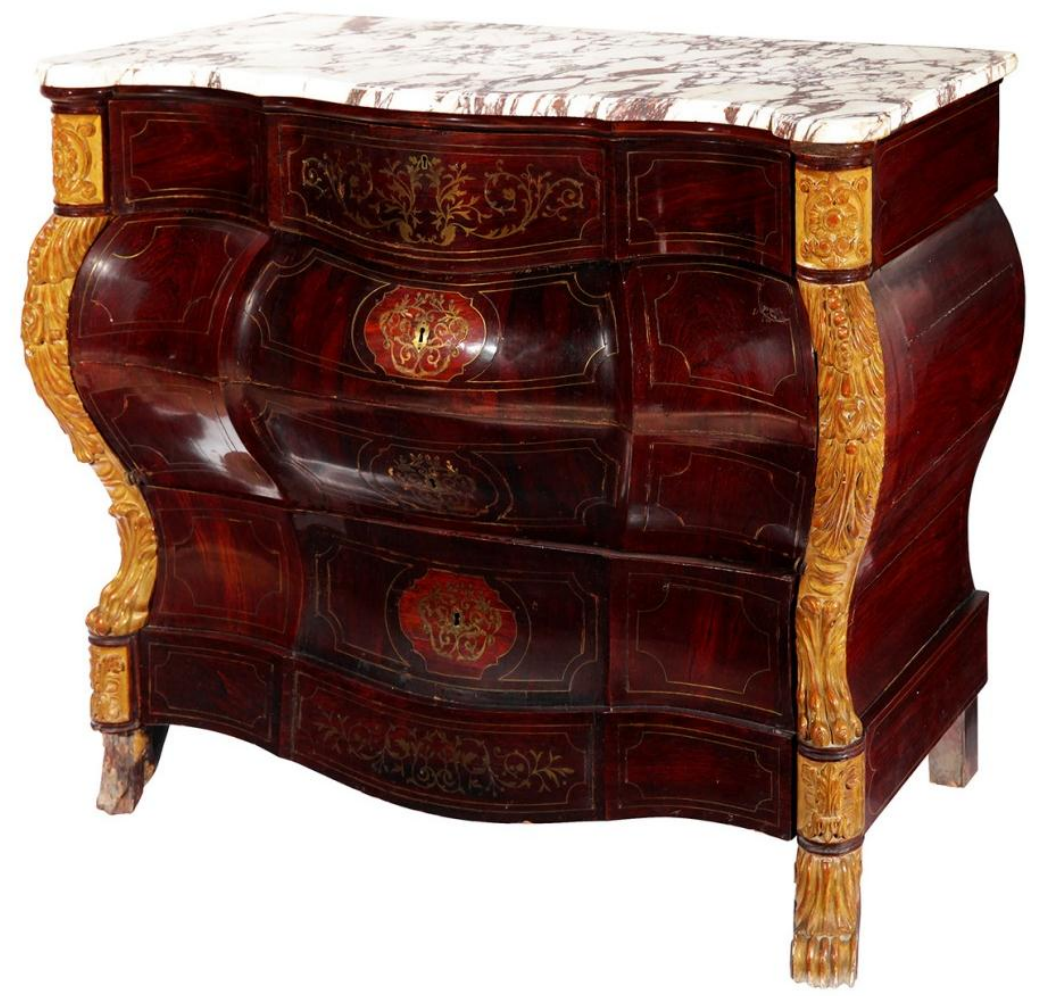

Fig. 12. Cómoda Isabelina de palisandro y marquetería metálica y carey, de hacia 1855.

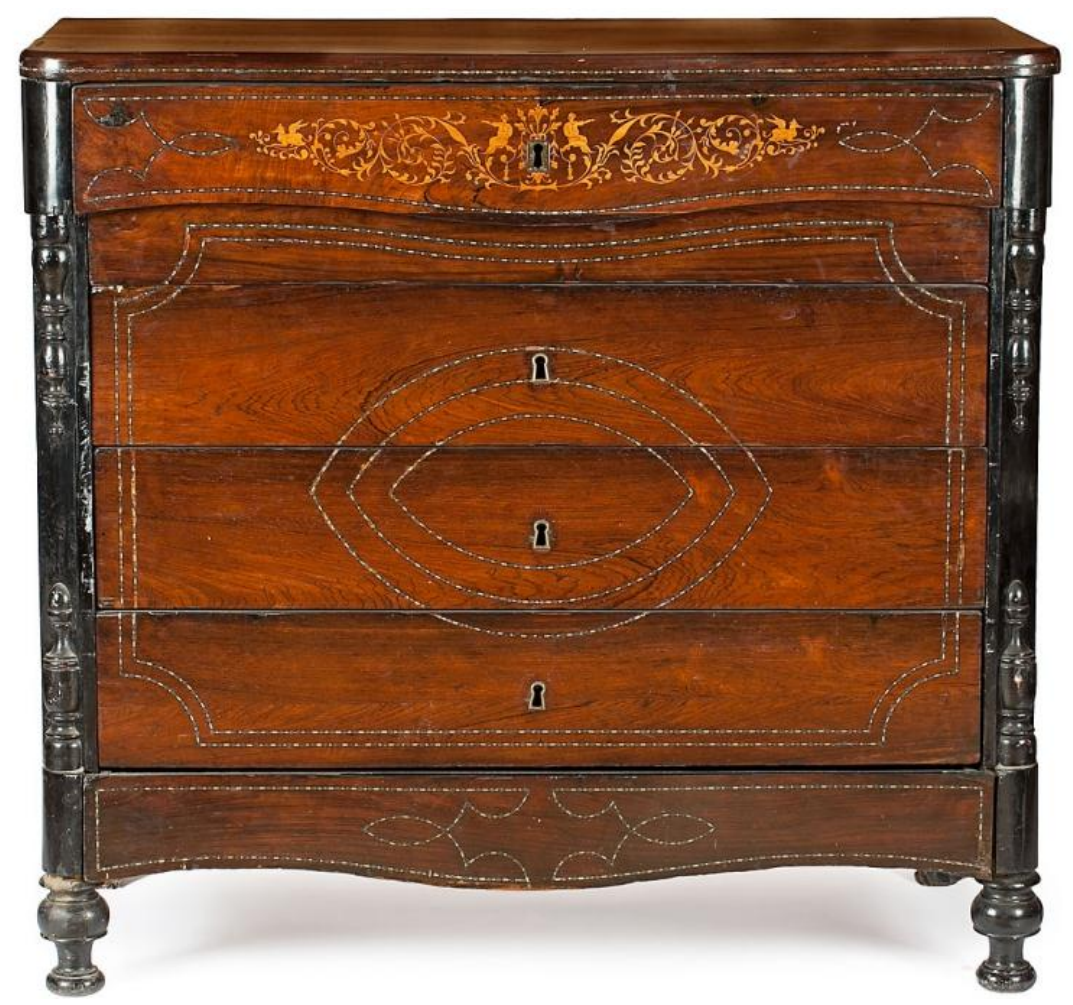

Fig. 13. Cómoda Isabelina de palisandro, marquetería de boj y chaflanes tintados, de hacia 1860. 


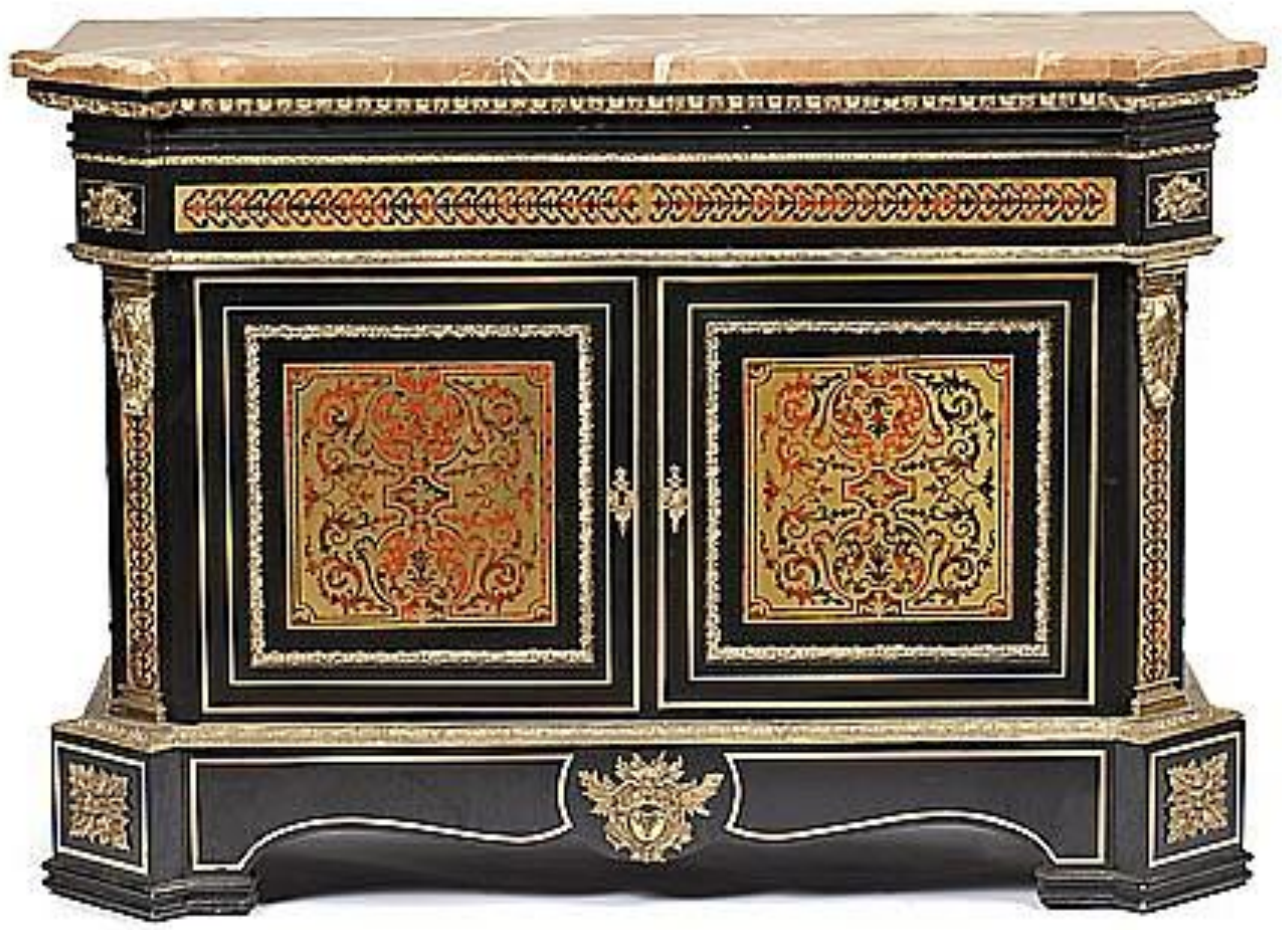

Fig. 14. Cómoda-entredós francesa de madera de ébano y marquetería tipo "Boulle”, de hacia 1860.

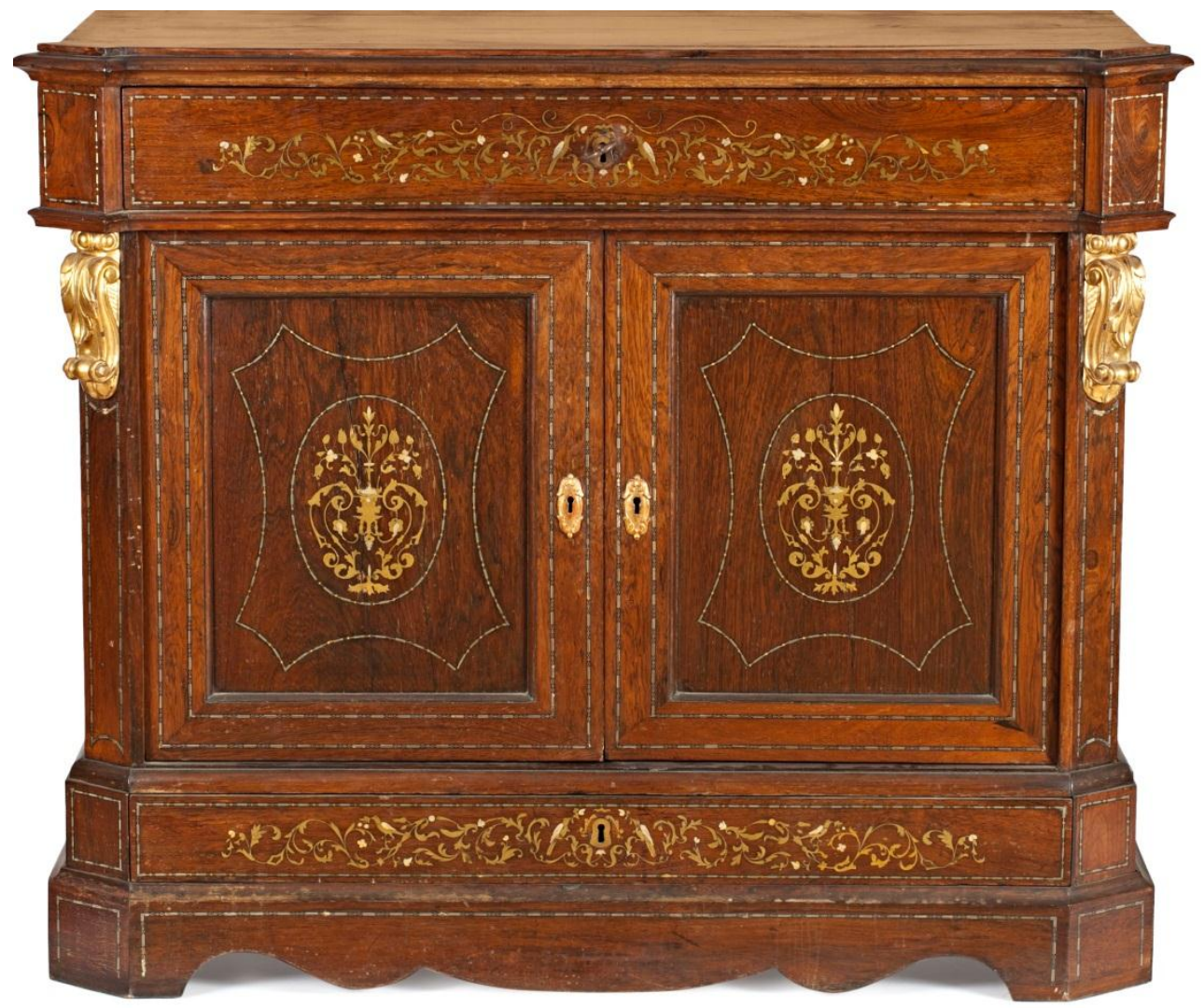

Fig. 15. Cómoda Isabelina con puertas de palisandro y marquetería metálica, de hacia 1860. 


\section{NOTAS}

${ }^{1}$ Catálogo de las Exposiciones Industriales de Barcelona, 1844, Imp. J.Tauló, Barcelona, 1844, p. 56.

2 Jean Bérain (Saint-Mihiel, Mosa, 1640 - París, 24 de enero de 1711) fue un dibujante, diseñador, pintor y grabador francés, principal fuerza artística de la oficina real de los «Menus-Plaisirs du Roi», en la que se hacían todos los diseños de la corte para espectáculos, fiestas y funerales, además de muchos diseños de mobiliario. Wikipedia.

${ }^{3}$ Catálogo de la exposición Industrial y Artística de productos del principado de Cataluña, Imprenta Narciso Ramirez, Barcelona, 1860, p. 50.

4 La expresión latina "horror vacui” (literalmente 'miedo al vacío') se emplea en la historia del arte, especialmente en crítica de la pintura, para describir el relleno de todo espacio vacío en una obra de arte con algún tipo de diseño o imagen. Wikipedia.

${ }^{5}$ Maque: "Barniz, de diferentes orígenes, que imitan al obtenido del árbol de la laca, con lo que se recubren las superficies de ciertos muebles". RODRÍGUEZ BERNIS, Sofía, Diccionario de mobiliario, Madrid, Ministerio de Cultura, 2006. 